\title{
Bem-vindos ao espetáculo: sentidos do trabalho para artistas circenses
}

\author{
Welcome to the show: meanings of work by circus performers \\ http://dx.doi.org/10.5007/2178-4582.2017v51n2p456
}

\section{Leticia Werner, Scheila Girelli e Márcia Luiza Pit Dal Magro \\ Universidade Comunitária da Região de Chapecó/SC, Brasil}

\begin{abstract}
Esta pesquisa buscou compreender os sentidos atribuídos ao trabalho por artistas circenses. A pesquisa seguiu a abordagem qualitativa, de cunho etnográfico. A observação participante e entrevistas semiestruturadas foram as principais ferramentas de busca de informações. Os artistas circenses se identificam com o trabalho que realizam, especialmente pela possibilidade da itinerância e saber profissional produzido na própria convivência, marcada pelo forte vínculo afetivo. As atividades caracterizamse pela autonomia, criatividade, liberdade para negociar suas necessidades e participar da tomada de decisões. Por outro lado, o trabalho é realizado informalmente, precarizando o acesso e garantia dos direitos trabalhistas e previdenciários. $\mathrm{O}$ circo constitui-se como um espaço de convivência social e laboral, não permitindo uma distinção clara entre tempo livre e de trabalho, relações sociais, profissionais e familiares. Este modo de (con)viver permite, apesar das dificuldades, a perspectiva de, pelo trabalho, dar continuidade à "magia do circo".
\end{abstract}

Palavras-chave: sentidos do trabalho; artistas; Circo.
This research sought to understand the meanings attributed to work by circus performers. The research followed a qualitative approach of ethnographic feature. The participating observation and semi-structured interviews were the main data collection methods. The circus performers identify themselves with the work they do, especially the possibility of traveling and the professional knowledge produced in their own living experience, marked by the strong affective bonding. The activities is characterized by autonomy, creativity, and freedom to negotiate their needs and participate in the decision-making. However, the work is done informally, making the access and guarantee of labor and social security rights precarious. The circus establishes itself as a social and labor living space, not providing a clear distinction between free time and work, social relationships, professional and families. This way of living (with) allows, despite the difficulties, the perspective of giving continuity to the "circus magic" by their work.

Keywords: Meanings of work; Performers; Circus.

\section{Introdução}

O circo constituiu-se historicamente como uma arte milenar. Dos saltimbancos, da estrutura de pau a pique até os grandes cenários e espetáculos atuais, o circo foi se adaptando, considerando as transformações políticas, econômicas, sociais e culturais pelas quais a sociedade também passou. Embora as mudanças sejam constantes, algo que sobrevive ao tempo é a imagem do circo como algo mágico.

Conforme Pines Junior et al. (2013, p. 01), "o circo é uma das mais antigas manifestações artísticas do mundo. O seu surgimento e desenvolvimento acompanham o processo histórico e filosófico das sociedades medievais, 
modernas e contemporâneas". Tem como meio de entretenimento a arte e seu trabalho está presente nos mais diferentes povos e culturas.

Para Castro (2005), os espetáculos circences tiveram início com o Império Romano, quando os anfiteatros eram ocupados por artistas que realizavam apresentações que incluíam animais, engolidores de fogo e gladiadores. Pines Junior et al. (2013) destacam que nos séculos IV e V os circos que tinham o modelo romano foram extintos, tendo em vista que a igreja da época defendia as práticas desses como pecaminosas. A partir de então, os artistas começaram a ser perseguidos e tiveram que mudar-se constantemente, criando a primeira característica do trabalho circense que está presente até hoje: a itinerância.

$\mathrm{Na}$ Europa da Idade Média era comum os artistas se reunirem em grupos familiares e se deslocarem de um vilarejo a outro, realizando apresentações em troca de abrigo e comida. Com o surgimento das cidades, os acrobatas, músicos, dançarinos e atores se encontravam em praças, campos e feiras, com o intuito de alegrar festas e demonstrar suas habilidades (COSTA, 1999).

Já no circo moderno, os espetáculos começaram a ser cercados e as pessoas passaram a pagar para assistir as apresentações. Com isso, surgiu o empresário, o dono do negócio e o espetáculo circence se tornou um produto. A chegada das primeiras troupes ${ }^{1}$ aos Estados Unidos no início do Século XIX também é um marco importante na criação do chamado circo americano, o qual ajuda a caracterizar o circo da forma como é conhecido nos dias de hoje. Costa (1999) afirma que o circo em suas viagens foi unindo línguas, costumes, saberes e mitos. "Diferentes grupos foram integrando-se como os adestradores e ouvires ciganos, os equilibristas chineses, ou os contorcionistas indianos" (COSTA, 1999, p. 39).

Torres (1998) aponta que no século XVIII muitos ciganos que fugiram da Europa, por estarem sendo perseguidos, vieram para o Brasil e, junto, trouxeram a cultura circense. Seus espetáculos incluíam dentre outras artes a doma de animais e o ilusionismo. Os artistas estrangeiros se utilizavam dos conhecimentos técnicos adquiridos em seus países de origem e buscavam adaptá-los de acordo com a realidade encontrada no Brasil. Esse conhecimento foi passado de geração para geração como é da tradição circense. De acordo com Costa (1999), o processo de adaptação e circulação do circo tem uma grande relação com a história da cultura brasileira.

Oliveira e Cavedon (2013) destacam que, segundo o Instituto Brasileiro de Geografia e Estatísticas (IBGE), na década de 1970 havia mais de dois mil circos no Brasil, número que se reduziu pela metade em 2000. Nesse período, 
os circos tradicionais diminuíram e os circos escolas aumentaram. Todavia, de acordo com os autores, é difícil destacar de forma precisa o número de circos existentes no país atualmente. Silva e Abreu (2009, p. 182) afirmam que a criação de escolas de circo modificou a história da arte circense, já que "[...] antes, os saberes do circo eram passados dentro do circo, nas escolas permanentes e itinerantes que eram os circos de lona; hoje, cada vez mais artistas se fixam em determinada cidade e passam seu conhecimento em troca de remuneração".

Apesar das transformações que a arte circense e seus modos de expressão vêm sofrendo nas últimas décadas, o circo e seus artistas ainda persistem, sendo uma atração que ainda mobiliza plateias em muitas cidades brasileiras. No entanto, o levantamento de informações em bases de dados ${ }^{2}$ indicou que, no Brasil, ainda são poucos os trabalhos acadêmicos que estudam o circo. Das publicações encontradas, grande parte se refere às áreas da Educação, História e, notoriamente, Artes. Raros são os estudos que buscam compreender os processos de trabalho, as relações sócio-profissionais, identificando os elementos da cultura circense e como isso afeta a constituição do sujeito que vive do trabalho do circo. Daí a importância deste artigo, o qual tem por objetivo compreender os sentidos atribuídos ao trabalho pelos artistas circenses.

O sentido pode ser descrito como, “[...] uma formação dinâmica, variável e complexa que tem zonas de estabilidade diferentes" (GONZÁLEZ REY, 2004, p. 38). O sentido define "' [...] o que o sujeito experimenta psicologicamente na experiência de um evento atual, aparecendo, assim, como uma fonte essencial da subjetividade" (Ibid., p. 39). Assim, essa categoria é tomada para nortear este estudo sobre a atividade do artista circense, a qual, de início já se pode reconhecer que é muito mais que um trabalho, caracterizando-se como um modo de vida.

\section{Método}

A pesquisa ora apresentada caracteriza-se como um estudo de cunho etnográfico, realizado em um circo instalado no município de Chapecó, Santa Catarina. De acordo com Godoy (1995), a pesquisa etnográfica [...] "parte do princípio que a descrição e compreensão dos significados de um evento social só são possíveis em função da compreensão das inter-relações que emergem dentro de um determinado contexto" (p. 28).

2 Google Acadêmico, Scielo, Lilacs, E-books, Bvs, Banco de Tese e Dissertações da Capes, Pepsic, Ibict, Enciclopédias, Psicodoc, site da Fundação Nacional de Arte - Funarte, utilizando as seguintes palavras chave: processos de trabalho; circo; relações profissionais; cultura circense; profissionais do circo. Como resultado desta consulta, constatamos que a maior parte dos estudos destaca a história e origem do circo no Brasil. 
A observação participante registrada em diário de campo e as entrevistas semiestruturadas foram as técnicas de pesquisa ${ }^{3}$ utilizadas para realizar o estudo. A aproximação com o campo de pesquisa se deu por meio do contato com um casal de artistas circenses que estavam procurando emprego na cidade anteriormente citada. Os mesmos aceitaram participar de uma entrevista exploratória, a qual permitiu a familiarização dos pesquisadores com o problema de pesquisa, na perspectiva apontada por Gil (2002). Esses artistas também indicaram como fonte de pesquisa, um dos circos que costumava se instalar na cidade, no qual ambos já tinham trabalhado.

A partir das informações que Benjamin e Justine 4 repassaram, buscou-se ampliar o conhecimento sobre este circo por meio das redes sociais. Conforme Aguiar (2007, p. 04), muitas pessoas utilizam essa ferramenta como fonte de pesquisa, denominada etnografia digital ou online, "[...] que compreende a observação dos sujeitos em seu processo de construção de percepções e comportamentos na relação social em rede".

Por meio de uma das redes sociais acessadas, encontrou-se uma página sobre o Circo Esperança. Nesta, entre outras informações, havia fotografias que registravam os espetáculos. Por meio de aplicativo que realiza marcação dos nomes das pessoas que estão nas fotos, foi possível encontrar os perfis individuais de alguns trabalhadores do respectivo circo, identificando relações de parentesco entre os mesmos, bem como a atividade que realizavam.

O contato telefônico do circo disponibilizado na internet permitiu conversar com um dos profissionais que atuava no mesmo. Foi quando se soube que eles estavam chegando na cidade anteriormente citada para uma nova temporada de apresentações. O primeiro contato dos pesquisadores com o circo foi como espectadores, no segundo dia de abertura do mesmo. A segunda visita ao espaço foi realizada no dia seguinte, para apresentar a proposta da pesquisa e obter o consentimento dos responsáveis para adentrar no campo. Com a abertura do espaço, nos inserimos no contexto para conhecer o cotidiano do circo, momento que iniciou a observação participante.

A observação participante ocorreu diariamente durante o período em que o circo permaneceu na cidade, o que correspondeu a trinta dias. Esta se deu durante os espetáculos, os ensaios, as conversas e demais atividades cotidianas. Durante a pesquisa de campo, foi possível inserir-se no cotidiano do circo e participar das atividades que ali aconteciam como as refeições que ocorriam de modo conjunto na cozinha, o cuidado das crianças, a visita às moradias.

3 O projeto de pesquisa foi aprovado no Comitê de Ética em Pesquisa com Seres Humanos, por meio do protocolo 201/2013.

4 Os nomes do circo, bem como dos artistas citados ao longo do trabalho, são fictícios. 
Ao todo, trabalhavam no Circo Esperança na ocasião da pesquisa 65 pessoas. Dessas, dez realizavam alguma atividade artística, sendo os artistas circenses eleitos como os principais sujeitos do estudo. Além da entrevista exploratória citada anteriormente, foram entrevistados mais 5 artistas do circo e também o dono do mesmo, totalizando seis entrevistas, as quais foram gravadas e posteriormente transcritas. As entrevistas aconteceram durante o período de observação nos espaços do circo. As informações foram analisadas a partir da psicologia sócio histórica, por meio dos núcleos de significação, propostos por Aguiar e Ozella (2006), os quais orientaram a estrutura deste artigo.

\section{Resultados e discussão}

"Quando comecei a caminhar, eu já fazia circo!": tradição na arte circense

O circo moderno no Brasil ficou conhecido por ser um modelo de circo tradicional e familiar, marcado por aspectos como o domínio da arte circense, cujo aprendizado é transmitido entre as gerações, os laços consanguíneos e afetivos do grupo que vive "embaixo da lona" e a itinerância. "Privilegiam um envolvimento exclusivo de toda a família com os afazeres do circo, seja na preparação de espetáculos, nos cuidados com a lona, e os materiais de trabalho, seja no processo ensino-aprendizagem desta arte" (BARONI, 2006, p. 06). Essa característica marca o contexto estudado em que o circo não se apresenta somente como um espaço de trabalho, mas familiar e também de moradia. Esse contexto compõe a vida dos sujeitos, e está atrelado as suas mais remotas experiências, constituindo os sentidos do trabalho do artista circense.

O Circo Esperança existe há 15 anos. Valdemar, o dono do circo, é a quinta geração que vive do trabalho circense. Quando cresceu, Valdemar diz ter optado por trabalhar em outro circo que não o de seus pais, tendo trabalhado com várias troupes, forma pela qual conheceu sua esposa, que também nasceu no circo. Depois de alguns anos, os dois resolveram abrir o próprio negócio. Os filhos do casal constituíram novas famílias que também trabalham no Circo Esperança.

Segundo Valdemar, inicialmente, o Circo Esperança era muito pequeno e contava com poucos trabalhadores. Com o passar do tempo, conseguiram organizar e ampliar sua estrutura física, aumentando, assim, o número de profissionais. Atualmente, o circo inclui crianças, adolescentes, jovens, adultos e idosos, de ambos os sexos. A maior parte destes mantém laços de parentesco entre si. 
A história do Circo Esperança e dos seus artistas aponta que o espaço mantém muito viva a tradição circense. De acordo com Costa $(1999$, p. 72$)$, o termo tradição, no universo circense, significa estar presente em um espaço "[...] onde um determinado tipo de conhecimento constitui a própria essência da instituição e chega a integrar às organizações por meio da vivência e da prática daqueles que por origem sanguínea ou não, constituem seu maior patrimônio: os indivíduos". Ainda, nesta mesma perspectiva, Silva (1996, p. 56) defende que "[...] ser tradicional significa pertencer a uma forma particular de fazer circo, significa ter passado pelo ritual de aprendizagem total do circo, não apenas de seu número, mas de todos os aspectos que envolvem sua manutenção".

Por meio das observações e entrevistas, notamos que manter a tradição circense é algo de grande valor para os sujeitos que ali vivem e trabalham. A fala descrita abaixo representa aspectos que estiveram presentes em muitas outras: os aprendizados proporcionados pela convivência no circo, em que se aprende o fazer, fazendo com os mais velhos. "Desde pequena eu fui aprendendo com as pessoas dos circos em que nós ficamos, foi na experiência, na dedicação, no dia a dia, nunca fiz nenhum tipo de curso, o que eu sei aprendi ensaiando muito." (Guilhermina, trapezista, 17 anos). Assim, muitos dos artistas circenses realizam a atividade desde criança, como também é demonstrado pela fala do palhaço: "Desde pequeno, quando comecei a caminhar, eu já fazia circo. Com quatro anos eu já me vestia de palhaço e entrava no picadeiro com o meu pai. Com oito anos comecei a fazer trapézio, com nove anos equilibrio em cabo de aço, e depois me fixei em palhaço. Hoje em dia só faço isso". (João Lorota, palhaço, 23 anos).

Segundo Costa (1999), o termo tradição é utilizado também no sentido de aceitação de um novo indivíduo ao grupo. De acordo com a autora, todos os valores do circo se assentam sobre a ideia de tradição, seja ela um pressuposto ou uma conquista. Assim, nem sempre um artista nasce em uma família circense, mas, ao se inserir neste contexto apropria-se do conhecimento e consegue desenvolver atividades artísticas, tornando-se um tradicional.

A característica que Costa (1999) salienta pode ser percebida nos relatos. Segundo um dos entrevistados, é comum às pessoas de circo se relacionarem e constituírem família com pessoas que vivem nas cidades onde o circo se apresenta, o que aconteceu, por exemplo, com os filhos do dono do circo. Muitas vezes, essas pessoas optam por ingressar no circo e acompanhar a sua jornada, tornando-se um tradicional, como aponta João Lorota: "minha esposa é da cidade, conheci ela e pedi em namoro, estamos juntos há seis anos. Dai ela virou bailarina, dançava junto com minha mãe" (João Lorota, palhaço, 23 anos). 
Costa (1999) ainda destaca que, admitir pessoas não nascidas entre dinastias tão bem preservadas é parte do processo de inclusão que sempre existiu no circo, desde o tempo em que existia apenas como uma das artes de rua. Essa inclusão permanente de novos elementos renova-o, atualiza-o e o faz próximo da sociedade que o cerca.

O núcleo familiar circense, ao mesmo tempo em que tem sua constituição idêntica aos outros grupos familiares, incorpora outra familiaridade - o conjunto das outras famílias que compartilham do mesmo saber secular: a arte (SILVA, 1996). Essa característica da ligação entre as pessoas do circo, na qual os sujeitos se identificam formando uma grande família, pode ser visualizada na fala de Beto (globista, 22 anos): "[...] eu me sinto em casa, aqui é um lugar bom de trabalhar, eles não me tratam como um funcionário, eles me tratam como um filho".

Uma das questões observadas que remete à identificação e proximidade dos trabalhadores circenses é como participam no cuidado das crianças que moram no circo. Durante a pesquisa, observamos que qualquer pessoa do circo, inclusive as pesquisadoras, depois de mais familiarizadas, auxiliavam no cuidado das crianças. O cuidado passava por atitudes como: observar se a criança está em perigo, se está com fome, sede, se está na hora de tomar banho, levar para a escola, entre outros.

A itinerância é outra característica da tradição circense. Mudar-se constantemente é uma característica circense, advinda desde os primórdios. Segundo Costa (1999), as mudanças fazem com que o circo molde sua própria estrutura, seus processos administrativos e suas estratégias de sobrevivência.

Autores como Costa (1999) utilizam o conceito itinerância como distinto de nomadismo destacando que "[...] nômades são grupos que por essência se organizam de forma tribal, seguem um líder e tem como referência o movimento continuo e permanente" (p. 14). Sua sobrevivência se dá a partir daquilo que encontram no local onde estão. Ainda, segundo o autor, o circo não vive de forma tribal, mas com uma união familiar em função de seu ofício: a arte. "Sua fidelidade é ao circo, entidade, instituição, identidade" (p. 15), não necessariamente à organização na qual está no momento trabalhando e vivendo. O elemento central que Costa (1999) apresenta sobre a diferenciação entre nomadismo e itinerância é a maior liberdade presente nessa última.

Ao contrário do nomadismo, as pessoas que vivem no circo trabalham onde quiserem e puderem, nada as prende em um único espaço. Exemplo disso, é a fala do casal circense que participou da pesquisa exploratória. Segundo os mesmos, ambos já haviam trabalhado em inúmeros locais ligados à cultura circense e gostavam muito das atividades que desenvolviam. Contudo, caso 
sentissem dificuldades ou não se adaptassem ao local, eles buscavam por um novo, em outra cidade ou Estado.

Como já mencionado anteriormente, a itinerância passa a ser uma das grandes peculiaridades que caracteriza o modo de viver dos profissionais circenses, constituindo-se, como observado nas entrevistas, em uma das grandes vantagens que os artistas reconhecem no trabalho circense, como expressa a fala a seguir: “[...] a experiência de conhecer novas culturas, novas pessoas, e o fato de estar sempre viajando para lugares novos e conhecendo pontos turísticos das cidades." (Guilhermina, trapezista, 17 anos). Todavia, o mudar-se constantemente também traz certas dificuldades, como explica Ana: "É ruim ficar longe, e não tem como visitar porque tem que trabalhar todo o dia, só se for em dia de mudança, mas ainda se a cidade for meio perto." (Ana, contorcionista, 20 anos).

\section{As atividades realizadas pelo artista circense}

Por meio da pesquisa observou-se que os artistas circenses desempenham várias atividades em seu cotidiano. As tarefas do dono do circo, por exemplo, estão mais voltadas à organização geral, administração do empreendimento: "Eu não apareço apenas na hora do espetáculo, durante o dia eu vou comprar e resolver as coisas do circo, eu vou comprar tinta, soldar as carretas, pagar a documentação, contratar artistas" (Valdemar, dono, 53 anos).

Além de realizar as atividades de ordem burocrática, Valdemar também atua nos espetáculos como apresentador e, por ser o dono, torna-se uma figura de referência para todos. Assim, em qualquer decisão ou problema sempre ele é chamado.

Os demais artistas desempenham como atividade principal o espetáculo. No entanto, suas atividades extrapolam em muito o momento da apresentação, englobando a preparação do número, a composição dos personagens, a confecção das fantasias, os ensaios e, em alguns casos, a venda de artigos no intervalo das apresentações e o auxílio na apresentação dos colegas artistas. Um exemplo da preparação do espetáculo pelo artista circense é o número apresentado pelo palhaço. Este é o que mais envolve interação com o público e demanda muita criatividade. De acordo com o artista, o trabalho e a apresentação não podem ser totalmente planejados: "Cinquenta por cento é organizado e cinquenta por cento é no improviso. Se o público é animado é dali que saem as ideias novas" (João Lorota, palhaço, 23 anos).

Os artistas não têm um horário definido para o ensaio. Alguns optam por ensaiar no período da manhã, outros a tarde e alguns até após os espetáculos, como destacado por uma das entrevistadas: "Quanto tem um tempinho para 
ensaiar, sempre ensaio de manhã ou depois do espetáculo que tem pouco barulho" (Ana, contorcionista, 20 anos).

É importante destacar, a partir do contexto observado, que praticamente todos os espetáculos precisam da ajuda dos colegas, especialmente para a organização dos instrumentos no momento da apresentação, o controle da música e iluminação do ambiente. Quando uma atividade se baseia em equipes ou troupes, todos precisam ter uma visão compartilhada.

Costa (1999) expõe que é o conjunto, é o trabalho em equipe que faz com que aconteça o brilho individual do artista e que ele consiga realizar a sua apresentação. Assim, é necessário que todos estejam voltados para a realização de um único objetivo, tendo a certeza que poderá contar com o outro caso um imprevisto aconteça e, assim, o outro saberá exatamente o que está acontecendo para agir a qualquer momento. "O que se estabelece entre as pessoas de uma troupe durante a realização de um número é uma sintonia tão perfeita, que se pode dizer que as pessoas são capazes de adivinhar pensamentos. Por isso, são capazes de tomar decisões rápidas e precisas em momentos críticos" (p. 113).

Ao longo dos espetáculos pudemos ver a cumplicidade estabelecida no desenvolvimento das atividades, especialmente pelo cuidado uns com os outros:

Meu pai sempre olha os aparelhos, ele é meu ponto seguro, eu sou muito desligada então meu pai me ajuda muito. Os guris que ficam organizando o material para as apresentações, a minha mãe que me ajuda no número de força capilar, é ela que amarra o cabelo. Eu sempre dependo de alguém para fazer o número, sozinha não consigo fazer nada. (Guilhermina, trapezista, 17 anos).

Essa proximidade que o artista tem com o seu ajudante é o que faz com que se sinta seguro. O conhecimento técnico dos números circenses não é de domínio de todos os trabalhadores. Em apresentações que são mais arriscadas, como o tecido acrobático e o trapézio, nem todos os trabalhadores podem auxiliar. Nesses casos, o ajudante deve deter um conhecimento técnico sobre o número e, observamos que na maioria das vezes, esses auxiliares são familiares, tais como irmãos, pais, esposo(a). Em conversa com uma das artistas a mesma destacou que naquele dia em sua apresentação, um detalhe do número tinha saído errado, mas que ela havia conseguido reverter. Ela destacou que o público geralmente não percebe, pois não tem esse conhecimento técnico, mas que o seu ajudante, que era o seu pai, havia percebido o erro. Assim, o que Costa (1999) destaca sobre a 
sintonia realmente é primordial, pois se algum imprevisto tivesse acontecido o seu pai estaria pronto para auxiliá-la.

Já em números que não são tão arriscados, os outros trabalhadores auxiliam com a organização dos materiais e dos equipamentos. O trabalho em equipe é fundamental para o artista realizar a sua apresentação, pois quando o artista entra no picadeiro, seu equipamento deve estar instalado e pronto para ser utilizado, a música que ele escolheu para aquela apresentação deve estar tocando, a iluminação adequada etc. Ou seja, o êxito das apresentações artísticas depende, essencialmente, da relação que estabelecem entre si, como grupo de trabalho. Assim como os artistas têm autonomia para prepararem seu número, observou-se que eles também participam de outras decisões sobre o trabalho no circo. As decisões quanto à próxima cidade em que o circo vai se instalar, os horários de abertura e funcionamento, o valor do ingresso, são tomadas pelo dono do circo. Todavia, observou-se que este pede a opinião dos trabalhadores. Como exemplo, podemos citar duas situações presenciadas durante a pesquisa: em uma delas, o dono do circo, mediante o diálogo com um dos trabalhadores da manutenção, anotou o pedido de compras de materiais. Quem efetivaria a compra dos mesmos seria o próprio dono, mas quem definiu a quantidade, a marca, as características do produto, foi o trabalhador que estava realizando a atividade.

Em outra situação, o dono conversou com os trabalhadores para ouvir a opinião deles sobre abrir ou não aquele dia em função da baixa temperatura. A grande maioria optou por não abrir e esta opinião prevaleceu. Assim, observamos que, apesar dos trabalhadores desenvolverem atividades muitos diferentes, há espaço para diálogo e algumas decisões, especialmente no que se refere ao trabalho coletivo, são tomadas pelo grupo.

\section{O corpo como instrumento de trabalho no circo}

Cada atividade de trabalho necessita de instrumentos específicos para ser realizada. Assim como o professor necessita dos livros, da lousa e do seu conhecimento para dar aula, os artistas circenses têm as suas peculiaridades. Alguns necessitam de grandes estruturas como o globo da morte, equipamentos específicos como no trapézio, o tecido acrobático. No entanto, indiferente da modalidade de apresentação, o corpo se torna o principal instrumento de trabalho.

Para Bolognesi (2001), muitos são os instrumentos de trabalho de um artista. Além das habilidades através dos números, há as coreografias desenvolvidas para incrementar as apresentações, música, efeitos de luz, as roupas e suas características, e o próprio corpo como matriz. 
A literatura tem na língua a sua matriz; a música, nos sons; a pintura, nas cores, traços e formas. Qual seria a matéria principal do espetáculo de circo? Linguagem, sons, cores, traços e formas dele participam, mas não chegam a ser fundantes. A matriz do circo é o corpo, ora sublime, ora grotesco. O corpo não é uma coisa, mas um organismo vivo que desafia seus próprios limites. (BOLOGNESI, 2001, p. 03).

Ao exibir o corpo, o circo rompeu com valores burgueses que apenas privilegiavam o espírito, o corpo passou a ser um instrumento de trabalho que até então era recriminado na sociedade. A beleza e a elegância da exibição dos corpos nos espetáculos são utilizadas como uma forma de sedução, mas também de brincadeira. "O corpo deixa de lado a roupa cotidiana que o esconde, para apresentar sua grandeza, no caso do acrobata, e sua deformidade, no caso do palhaço. Espetacularmente, o corpo se desnuda para revelar, a partir de polos opostos, toda sua potencialidade" (BOLOGNESI, 2001, p. 159).

No circo Esperança, vários foram os números observados durante a pesquisa, os quais dependem diretamente do uso do corpo do artista. Entre eles se pode destacar contorcionismo, malabarismo, equilibrismo, trapézio, arco aéreo, tecido acrobático, acrobacias sobre objetos, globo da morte e o número realizado pelo palhaço.

O contorcionismo, realizado por Ana (20 anos), inclui acrobacias que envolvem flexões e contorções, exigindo fluidez e criatividade na preparação do espetáculo, como foi possível observar nos ensaios. A acrobata diz que aprendeu o ofício com seu pai e que começou a desenvolver as habilidades corporais necessárias para o contorcionismo ainda muito pequena: "Desde os dois anos de idade eu já comecei a praticar, observava também as pessoas dos outros circos e fui desenvolvendo desde criança. Mas se você não começa quando pequena fica mais difícil depois".

Caramês e Silva (2011, p. 01) destacam que o corpo para os artistas circenses é e deve ser "um corpo móvel, livre, leve, ágil [...] desafiado a um exercício de olhar, que se constrói, que informa, envolve encanta [...]uma trama de imagens, figuras, formas, sons, fantasias, gestos e sonhos que são possíveis no mundo circense". A fala de Guilhermina (trapezista, 17 anos) corrobora tal afirmação, quando trata das exigências para o corpo frente aos números que realiza:

A mulher para entrar no picadeiro precisa estar com o corpo em dia, por que o público percebe e nota e também acaba comentando. A questão do corpo conta muito, quando eu dou uma engordadinha eu nem preciso subir na balança para saber 
que engordei. Eu percebo no próprio número pela questão do peso. (GUILHERMINA).

Ligado ao corpo, outro instrumento essencial nas apresentações circenses, que faz com que o circo se diferencie de outros ambientes de trabalho e o artista se diferencie das demais pessoas no próprio circo, são as roupas. Como exemplo, podemos citar a trapezista Guilhermina:

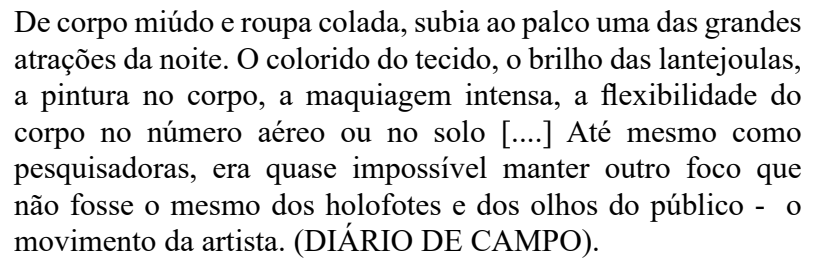

Observa-se que o brilho e o colorido se tornam ferramentas para que os artistas ganhem mais visibilidade distinguindo-se dos demais, tornando-se a peça central do espetáculo naquele momento. Como Guilhermina, as demais mulheres que se apresentam sempre utilizam maquiagens fortes e destacadas com muitas cores e brilho, além de acessórios para composição de suas roupas. A maioria dos artistas entrevistados organiza as suas roupas, sendo que alguns deles confeccionam a própria vestimenta.

As roupas e as pinturas contribuem para "incorporar" o personagem que o artista está fazendo, tornando-se, assim, mais fácil realizar as apresentações. Em uma conversa com um dos artistas o mesmo destacou ser muito tímido fora do picadeiro e que só consegue realizar as apresentações, pois, está vestido com o seu personagem. Segundo João Lorota, quem está no picadeiro é o personagem, não a pessoa, e a roupa e pintura auxiliam o mesmo para conseguir desenvolver o seu trabalho. "As vezes termina a última reprise do palhaço eu tiro a pintura venho aqui para frente para ajudar nas vendas e ninguém [referindo-se ao público] me conhece".

\section{Vínculo de trabalho e remuneração: "Eu escolhi o circo para ser minha casa e meu trabalho..."}

Os sentidos do trabalho artístico são marcados por especificidades como o intenso engajamento do artista que sugere, como apontam Bendassolli e Borges-Andrade (2015, p. 78), "um sentimento de profunda integração com o objeto de sua atividade". Assim, observamos que vida, trabalho e arte se confundem para os artistas circenses estudados. Mesmo assim, a relação entre produção artística e mercado se impõe para esses trabalhadores. 
A precariedade do vínculo empregatício é uma característica muito presente no trabalho artístico no Brasil, como indica o estudo de Segnini (2007). No circo Esperança essa realidade se confirma, sendo não havia nenhum tipo de registro em carteira de trabalho ou outra forma de contrato que estabelecesse vínculo empregatício formal dos trabalhadores estudados. Assim, estes não têm a garantia de acesso aos direitos trabalhistas e previdenciários, tais como aposentadoria por tempo de trabalho, auxílio doença, entre outros.

Conforme Alves (2001), o setor informal pode ser caracterizado de diversas formas, dentre as quais duas modalidades se destacam no espaço em que a pesquisa foi realizada. O trabalho informal "estável", em que os trabalhadores que são detentores de um conhecimento específico, caso dos artistas circences, que exercem o controle sobre a elaboração e execução do(s) número(s) que realizam. Essa "estabilidade" não diz respeito ao vínculo de trabalho que também é precário, mas ao domínio de um saber-fazer específico. E o trabalho informal "instável" cujos trabalhadores "[...] dependem de ocupação eventual, de sua força física e da disposição para realizar pequenas e diversificadas tarefas de pouca qualificação", (p. 212) que podem ser descritos como algumas atividades desenvolvidas pelos "peões"5 do circo.

A outra caracterização descrita por Alves (2001) são os trabalhadores informais "ocasionais/temporários", que desenvolvem atividades por um tempo previamente determinado em um espaço de trabalho. Essa característica da informalidade também está presente no circo Esperança, que geralmente contrata pessoas da cidade em que está instalado, pelo tempo em que o circo permanece nesta.

Por desenvolver a arte circense, os artistas são o elemento central do trabalho do circo. Valdemar destaca que "para que o circo seja bom, é necessário ter um bom espetáculo, e para que isso aconteça é necessário ter bons artistas." Assim, bons artistas passam a ser disputados no universo circense, possibilitando a escolha entre distintos circos que estão em funcionamento na região. Geralmente, os números que exigem mais domínio técnico e artístico têm mais valor de mercado. No entanto, foi observado que as habilidades bastante específicas do artista circence, pouco requeridas no mercado de trabalho formal, também favorece para que esses trabalhadores aceitem a condição de informalidade, pelo receio de não conseguirem outro espaço de trabalho e moradia.

No Circo Esperança o artista é contratado pelo tipo e/ou quantidade de número(s) que sabe desenvolver. Quanto mais difícil, perigoso e complexo

5 Os peões, segundo o dono do circo, são funcionários responsáveis pela organização da estrutura física do circo, a montagem, desmontagem e manutenção dos equipamentos. Além disso, auxiliam em qualquer outra atividade necessária, como na venda de ingressos e de alimentação durante o espetáculo. 
o espetáculo, maior a remuneração. $\mathrm{O}$ contrato com os artistas é feito por temporada. Após o término da mesma, ocorre uma nova negociação: se o dono gostou das apresentações ele faz uma nova proposta, e aí o artista é quem escolhe se quer continuar com o circo ou procurar outro espaço. Os contratos verbais realizados com os trabalhadores, segundo João Lorota (palhaço, 23 anos), às vezes, não são cumpridos, e a informalidade do vínculo dificulta o acesso aos direitos trabalhistas.

Em relação à remuneração, cada trabalhador é pago semanalmente. Segundo Valdemar, todos os circos pagam dessa forma: "Eles são pagos por semana porque é uma tradição do circo, para que nunca fiquem com o poço vazio". A remuneração é estipulada pelo mês e dividida nas semanas, somadas às vendas. Não existe uma padronização da remuneração entre os artistas. Tudo depende do acordo feito com o dono do circo. A maioria dos trabalhadores participantes do estudo destacaram estarem satisfeitos com a remuneração que recebem. Todavia, alguns se queixaram por desenvolverem atividades além do que foi acordado quando do seu ingresso, como aponta a seguinte fala: "Tem coisas que eu faço que eu não era contratada para fazer. Por exemplo, às vezes eu faço dois números por espetáculo, isso não era combinado." (Guilhermina, trapezista, 17 anos).

Além da remuneração fixa, alguns trabalhadores têm outra fonte de renda que são as vendas de alimentos e brinquedos no período em que o circo está aberto ao público. Nas combinações iniciais para o ingresso do trabalhador, já se estipula qual será o tipo de produto vendido e a porcentagem recebida sobre a venda. Cada trabalhador é responsável pela organização e pela oferta do produto que vende. Quanto maior a venda, mais lucro tanto para o trabalhador como para o dono. Algumas vendas são 100\% dos trabalhadores, mas a grande maioria é dada certa porcentagem ao dono. Em alguns casos, o valor adquirido pela venda desses produtos é maior que a remuneração pela apresentação, como pode ser observado na fala de um dos entrevistados: "No circo além do valor que você recebe para fazer as atividades, você tem as vendas. Aí se você pega uma cidade boa, às vezes você tira o triplo do valor que a gente ganha, e aquilo que você vende fica para ti”. (Benjamin, palhaço, 25 anos). Essa atividade que extrapola o trabalho artístico mas que incrementa a renda, foi valorizada pelos participantes do estudo como algo positivo.

No Brasil, o acesso a direitos como aposentadoria, pensões, auxílio-doença, salário maternidade entre outros, estão condicionados à inserção no mercado de trabalho formal (BOSCHETTI, 2008). Assim, alguns trabalhadores destacam que a informalidade se constitui como uma grande dificuldade, pois, por não terem a garantia dos seus direitos, não tem a segurança daquilo que possa acontecer no futuro. Exemplo disso é a possibilidade de, por um eventual 
problema ou acidente de trabalho, não conseguirem mais trabalhar, ficando sem nenhum tipo de fonte de renda para sustentar-se. Isso é reforçado pela observação de que, apesar dos artistas destacarem que ocorre a conferência de todos os equipamentos antes das apresentações, os números que realizam são arriscados e, exceto no número do "Globo da Morte", nos demais não havia nenhum equipamento de proteção individual, como capacete, por exemplo.

Ao longo da pesquisa apenas uma das artistas destacou ter sofrido um acidente grave em uma apresentação, mas diz que na época ainda era criança, o que também chama a atenção para outra questão que perpassa este contexto laboral que é o trabalho infantil. Durante o período em que a pesquisa foi realizada observou-se a presença de crianças em alguns números de espetáculos, a exemplo de apresentações teatrais. A tradição presente nesta atividade, em que o ofício é passado de pai para filho e em que as crianças se inserem desde cedo nas atividades, aprendendo a fazer com os mais velhos, faz com que seja comum a presença de artistas mirins nos espetáculos circenses, como pode ser observado nos próprios relatos dos artistas sobre suas histórias de vida. Sobre esta questão, Peres e Robortella (2013) tecem algumas análises sobre a proteção de crianças e adolescentes no que diz respeito ao trabalho artístico, e as diferenças que esse pode ter dos demais trabalhos infantis.

A precariedade do vínculo faz com que alguns trabalhadores optam por ser contribuintes autônomos, para mais tarde conseguirem seus direitos previdenciários. Outros, ainda, optam por armazenar parte de suas fontes de rendas como uma garantia, e ainda alguns se submetem a continuar trabalhando sem qualquer ação que venha prevenir esta situação. Mendes e Campos (2004) destacam que "a pressão da necessidade de sobrevivência submete o trabalhador, deixando em segundo plano todas as demais reivindicações de vida e trabalho, além do desconhecimento de direitos básicos e de mecanismos de proteção jurídica à cidadania" (MENDES; CAMPOS, 2004, p. 215). Este último aspecto mencionado pelas autoras, também foi percebido ao longo da pesquisa, em que ficou claro que alguns trabalhadores circenses desconhecem seus direitos trabalhistas.

Dentro do contexto circense a informalidade como condição de trabalho foi visualizada. Mas deve ser analisada de forma cuidadosa. O circo, embora sendo uma personalidade jurídica, constitui-se como um espaço, na maioria de seus aspectos, diferenciado do mercado formal. Os aspectos relacionados à cultura e tradição circense anunciam que a informalidade sempre esteve presente neste contexto de trabalho. Talvez, este aspecto esteja diretamente atrelado ao fato de que, para manter-se no circo como morador e trabalhador, é preciso, como mencionado pelo próprio dono, manter relações de convivência, pautadas no respeito, ajuda mútua, solidariedade e confiança. Tais sentimentos 
e vivências parecem estar imbricados na construção dos sentidos do trabalho circense.

A negociação permanente sobre o trabalho, uma certa liberdade de ir e vir entre um e outro circo, entre uma e outra cidade, entre um e outro número artístico, são aspectos importantes deste modo de significar o trabalho no circo e nem sempre presentes nos espaços formais do mercado de trabalho. Compreendemos que tais elementos são grandes motivadores da permanência dos artistas no universo circense estudado, o que não quer dizer, necessariamente, estar sempre no mesmo circo.

\section{Imagino meu futuro no circo}

No contexto estudado, a trajetória profissional como artista está muito atrelada ao circo. Todos os entrevistados nasceram, cresceram, acompanharam o circo, tendo o mesmo presente em suas vidas desde a infância. Alguns, mesmo com opção de realizar outras atividades, se mantiveram junto à família, na atividade circense. "E eu tive que optar por fazer alguma coisa na vida. Eu até tive oportunidade de estudar, mas eu não quis fazer curso, faculdade. Eu optei pelo circo, minhas expectativas no circo é ser um bom artista, um bom acrobata, um bom ator" (Benjamin, palhaço, 25 anos). Nesta mesma direção, outros têm como um objetivo futuro serem donos de um circo. "Eu me imagino no circo, quem sabe até ser dono de um circo" (Beto, globista, 22 anos). "Sempre no circo, tendo o meu próprio circo, não grande, uma coisa pequena" (João Lorota, palhaço, 23 anos).

Todavia, diferente destes que têm a certeza que querem trilhar o caminho no mundo circense, alguns ainda mostram indecisão quanto ao futuro, como pode ser visualizado na fala de uma das entrevistadas: "Meus planos são de: formar-me em uma faculdade e trabalhar na área, no futuro. Mas também, se eu ficar no circo também estarei feliz. Não sei dizer, porque para mim é meio incerto ainda. Mas, eu quero ter a experiência de viver fora do circo. Mas, também não sei se eu iria me acostumar." (Guilhermina, trapezista, 17 anos).

Costa (1999) destaca que dentro do mundo circense a identificação com o espaço é algo primordial. Todavia, não se refere apenas a atividade que a pessoa desempenha naquele momento, mas sim, ao circo como um todo. Mediante esta identificação, é muito comum que mesmo que a pessoa saia de um determinado circo, ela migre para outro. Tal situação pode ser visualizada a partir da fala seguinte:

Já trabalhei no mínimo em uns sete circos. O que fazia a gente sair dos circos eram propostas de outros circos. As vezes não estávamos bem em um circo e íamos para outro, um salário 
melhor, a convivência com o pessoal do circo. [...] Optamos por retornar porque nós já conhecíamos o pessoal daqui e também tivemos uma boa proposta para voltar, então voltamos. (GUILHERMINA, trapezista, 17 anos).

Observamos que a intenção de permanência no local está ligada a um sentimento de pertencimento ao universo circense. Em linhas gerais, todos os artistas visualizam o seu futuro no circo, desenvolvendo suas atividades, aprendendo outras artes circenses, denotando mais uma vez a tradição proeminentemente forte, por ser um circo tradicional, e o sentido do trabalho para estes artistas expressam que o circo configura-se acima de tudo como um modo de vida. "O fato de estar no picadeiro, ver todo o público olhando para a gente. Os aplausos, ver o sorriso da criança, a gente mesmo se diverte vendo os outros se divertirem." (João Lorota, palhaço, 23 anos). "A melhor sensação é ver os aplausos do público, dá uma gratificação pelo meu trabalho". (Guilhermina, trapezista, 17 anos). "Eu aprecio tudo a cada novo dia. Espetáculo por espetáculo. Eu me visto da melhor que eu posso me vestir. Divirto-me junto com o público e o nosso maior espetáculo é ver o público nos assistindo e por isso me acho uma pessoa vitoriosa por aquilo que faço." (Valdemar, dono, 53 anos). Nesse sentido, o reconhecimento do trabalho pelo público, em sua dimensão estética, como afirma Dejours (1997), foi um aspecto que se destacou como importante para atribuir sentido ao trabalho do artista circense.

A saída do circo para espaços formais do mercado de trabalho é menos comum. Muito disso, deve-se à identificação com o contexto circense, mencionada por Costa (1999), o que leva a dificuldade de adaptação a outros meios:

\begin{abstract}
Eu tentei morar na cidade. Fiquei dois anos morando em uma cidade, mas não é a mesma coisa é muito diferente. Eu trabalhei em um restaurante, fiquei uma semana eu tentei, mas não consegui, não é comigo. Aí eu comecei a trabalhar com o meu tio que ele montou uma equipe com a familia dele, que foi o que fez com que eu ficasse na cidade todo esse tempo, porque senão eu já tinha saído faz tempo. Eu trabalhava, nas escolas, fazia as apresentações de contorcionismo e isso eu gostava de fazer. (Ana, contorcionista 20 anos).
\end{abstract}

Silva (1996) ainda destaca que o conhecimento aprendido e transmitido dentro da organização circense é exclusivo daquele universo, e tem relação com a história de cada indivíduo. Para a autora, "Nada substitui ou supera a importância de ser cada indivíduo o depositário de um saber ancestral e iniciático". (p.79). Todavia esse conhecimento artístico aprendido pelos 
ensinamentos dos mais velhos é algo que o artista comprova pela prática e não por meio de certificados ou diplomas, comumente utilizados nos espaços formais de trabalho.

\section{Considerações finais}

Essa pesquisa partiu do entendimento do circo enquanto organização laboral, objetivando compreender os sentidos do trabalho para os artistas que compõe este cenário.

Constatou-se um grande diferencial do trabalho no circo em relação aos espaços do mercado formal, especialmente no que se refere à organização e relações de trabalho. Quanto à organização, prevalece a flexibilidade relacionada às normas, ao desempenho e aos resultados. Tais aspectos influenciam na construção da autonomia frente aos processos de organização e gestão do trabalho. A realização do trabalho do artista circense exige a compreensão e domínio do processo como todo, passando desde a escolha da música, o tempo da apresentação, as vestimentas, os equipamentos, a definição do número artístico etc. Além do conhecimento técnico do que desenvolvem, os artistas detêm seu principal instrumento de trabalho: o corpo. Em todos estes aspectos, são notórios a liberdade de criação e o processo de ensino/aprendizagem como permanente no cotidiano. Fruto deste contexto, as relações sócio-profissionais são marcadas pela afetividade, vínculo e confiança mútua. A possibilidade de diálogo com a gestão para negociar suas necessidades e participar da tomada de decisões contribuem para o sentimento de pertencimento ao que denominam ser "uma grande família".

Embora seja um espaço de entretenimento aos olhos do espectador, assim como outra organização de trabalho qualquer, existem dificuldades. As mais destacadas pelos trabalhadores referem-se a distância de familiares e amigos e a continuidade nos estudos. A informalidade que acompanha o trabalho dos artistas, revela ambiguidades. Por um lado, não é reconhecida como um problema, estando ligada a própria origem e configuração do trabalho no circo. Por outro, limita o acesso e garantia aos direitos trabalhistas e previdenciários, revelando a precarização. Apesar de tais evidências, prevalece a identificação dos artistas com o trabalho realizado, implicando diretamente no planejamento do futuro. Este aparece atrelado à perspectiva de permanência no espaço circense, destacando-se o desejo de qualificar as apresentações, aprender novos números, ensinar futuras gerações e ser dono do próprio circo.

Diante de tais apontamentos, os sentidos atribuídos pelos artistas circenses ao trabalho não se constituem como algo único, definido e completo. Mas, comporta a contradição, a parcialidade, o que podem ser indicadores de como 
cada sujeito experiencia sua vivência. Assim, simultaneamente, mantém aspectos da tradição e do contemporâneo, zonas de estabilidade e ruptura, que vão delineando formas de pensar, sentir e agir que configuram não só o trabalho como também o modo de vida do artista circense.

Aos pesquisadores que tenham interesse pelo tema, indica-se a continuidade do estudo, podendo ampliar a discussão sobre questões que não foram desenvolvidas por não serem o foco deste estudo, mas que se acenaram no campo de pesquisa, como: trabalho infantil circense; o processo de ensino e aprendizagem das crianças e adolescentes circenses que frequentam escolas públicas ou particulares de forma regular; a saúde do trabalhador, incluindo os aspectos psicológicos e jurídicos das relações de trabalho no espaço circense e os sentidos do trabalho para os outros trabalhadores do circo, que não os artistas.

\section{Referências}

AGUIAR, S. Redes sociais na Internet: desafios à pesquisa. In. XXX Congresso Brasileiro de Ciências da Comunicação, Anais...Santos/SP: Intercom - Sociedade Brasileira de Estudos Interdisciplinares da Comunicação . 2007. Recuperado de http://www.intercom.org.br/papers/ nacionais/2008/resumos/R3-1977-1.pdf.

AGUIAR, W. M. J.; OZELLA, S. Núcleos de significação como instrumento para a apreensão da constituição dos sentidos. Psicologia Ciência e Profissão, v. 4, n.12, p. 222-245, 2006.

ALVES , M. A. Setor informal ou trabalho informal? Uma abordagem crítica sobre o conceito de informalidade. (Mestrado em Sociologia) - Instituto de Filosofia e Ciências Humanas, Universidade de Campinas, São Paulo, 2001. 166f.

BARONI, J. F. Arte circense: a magia e o encantamento dentro e fora das lonas. Pensa a Prática, v. 9, n. 1, p. 81-99, 2006.

BENDASSOLLI, P. F.; BORGES-ANDRADE, J. E. Significado, sentido e tensões no trabalho artístico. Revista de Psicologia Organizacional e do Trabalho, v.15, n. 1, p. 71-81, 2015.

BOLOGNESI, M. F. O corpo como princípio. Transformação, v. 5, n. 24, p. 101-112, 2001.

BOSCCHETTI, I. Seguridade Social na América Latina. In: BOSCHETTI et al. (Orgs.). Política Social no Capitalismo: tendências contemporâneas. São Paulo: Cortez, 2008, p. 174195.

CAMPOS, M. Identidades e informalidade: um estudo com trabalhadores do setor informal de Florianópolis. (Mestrado em Psicologia) - Centro de Filosofia e Ciências Humanas, Universidade Federal de Santa Catarina. Florianópolis, 2005. $96 \mathrm{f}$.

CAMARÊS, A. S.; SILVA, D. O. Cultura circense, corpo e suas relações com o capitalismo. EFDeportes.com Revista Digital, v.16, n. 160, p. 1-2, 2011. Recuperado de www.efdeportes. com/efd160/cultura-circense-corpo-e-capitalismo.htm. 
CASTRO, A. V. Elogios da bobagem: palhaços no Brasil e no mundo. Rio de Janeiro: Editora Família Bastos, 2005.

COSTA, M. M. F. O velho-novo circo: um estudo de sobrevivência organizacional pela preservação de valores institucionais. (Mestrado em Administração Pública) - Escola Brasileira de Administração Pública, São Paulo, 1999. 204f.

DEJOURS, C. O fator humano. Rio de Janeiro: FGV, 1997.

GIL, A. C. Como elaborar projetos de pesquisa. São Paulo: Atlas, 2002.

GODOY, A. S. Introdução à pesquisa qualitativa e suas possibilidades. RAE- Revista de Administração de Empresas, v. 35, n. 2, p. 57-63, 1995.

GONZÁLEZ REY, F. L. O social na Psicologia e a Psicologia Social: a emergência do sujeito. Petrópolis: Vozes, 2004.

MENDES, R.; CAMPOS, A. C. C. Saúde e segurança no trabalho informal: desafios e oportunidades para a indústria brasileira. Revista Brasileira de Medicina do Trabalho,v. 2, n.3, p. 209-223, 2004.

OLIVEIRA, J. S.; CAVEDON, N. R. Micro políticas das práticas cotidianas: Etnografando uma organização circense. RAE - Revista de Administração de Empresas, v. 53, n. 2, p. 156-168, 2013.

PERES, A. G; ROBORTELLA, L. C. A. Trabalho artístico da criança e do adolescente: valores constitucionais e normas de proteção. Rev. TST, v. 79, n. 1, p. 159-180, 2013. Recuperado de http://www.fnpeti.org.br/arquivos/biblioteca/e2a2992a371794e1c16c68e3e9fe8fd1.pdf.

PINES JUNIOR, A. R. et al. O circo moderno: história, inovação e transição social. FiepBulletinOnLine, v. 83, edição especial, p. 1-6, 2013. Recuperado de http://www. fiepbulletin.net/index.php/fiepbulletin/article/viewFile/2981/5815

SEGNINI, L. R. P. Criação rima com precarização análise de mercado de trabalho artístico no Brasil. In: Anais...do XII Congresso Brasileiro de Sociologia, Universidade Estadual de Campinas, SP, 2007. Recuperado de http://beta.idanca.net/wp-content/uploads/2008/03/ liliana.pdf

SILVA, E. O circo: suas artes e seus saberes. O circo no Brasil do final do século XIX a meados do século XX. (Mestrado em História) - Instituto de Filosofia e Ciências Humanas, Universidade Estadual de Campinas, São Paulo, 1996. 184f.

SILVA, E.; ABREU, L. C. Respeitável público... o circo em cena. Rio de Janeiro: FUNARTE, 2009.

TONI, M. Informalidade. In: CATTANI, A. D.; HOLZMANN, L. (Orgs). Dicionário de Trabalho e Tecnologia. Porto Alegre: URGS, 2006. p. 157-161.

TORRES, A. O circo no Brasil. Rio de Janeiro: FUNARTE, 1998. 
Submissão em: 28/03/2017

Revisão em: 31/05/2017

Aceite em: 18/06/2017

Leticia Werner é graduada em Psicologia. Universidade Comunitária da Região de Chapecó - Unochapecó. E-mail: letiwerner@unochapeco.edu.br.

Scheila Girelli é mestre em Psicologia. Professora da Área de Ciências Humanas e Jurídicas, Curso de Psicologia, Universidade Comunitária da Região de Chapecó Unochapecó. E-mail: scheilapsi@unochapeco.edu.br.

Márcia Luiza Pit Dal Magro é doutora, professora do Programa de Pós-graduação em Políticas Sociais e Dinâmicas Regionais da Unochapecó. Universidade Comunitária da Região de Chapecó - Unochapecó. E-mail: mapit@unochapeco.edu.br 